\title{
Exploring Normative Creativity: Testing the Relationship Between Cognitive Flexibility and Sexual Identity
}

\author{
Julie Konik $^{1,3}$ and Mary Crawford ${ }^{2}$
}

\begin{abstract}
Brown (1989) proposed that lesbian, gay, and bisexual individuals possess greater "normative creativity" and flexibility than heterosexuals because they have fewer norms for living in heterosexually dominated society. In this article we explore one possible individual difference between heterosexuals and nonheterosexuals in the domain of normative creativity by examining the relationship between cognitive flexibility and sexual identity among 358 university students. Participants with sexual identities not directed toward one gender exclusively (e.g., bisexual, biaffectionate, or queer) scored significantly higher on a measure of cognitive flexibility than did heterosexual and gay/lesbian participants; the latter two groups did not differ from each other. These results suggest that it is having a nonexclusive sexual identity, rather than a lesbian or gay identity, that is related to greater cognitive flexibility.
\end{abstract}

KEY WORDS: cognitive flexibility; bisexuality; homosexuality; sexual identity.

Psychology has undergone a radical shift in its conceptualization of lesbian, gay, and bisexual (LGB) sexual minorities. Until 1973, homosexuality was pathologized and listed in the Diagnostic and Statistical Manual of Mental Disorders (DSM; Bayer, 1987). However, the depathologizing of homosexuality did not immediately lead either to mainstream conceptualizations of LGBs as psychologically healthy or to the integration of LGB samples into psychological research. Rather, as Brown (1989) noted, lesbian and gay issues were "not in the core curriculum in reality or emotionally" (p. 446).

In light of the marginalization of LGB psychology, researchers (e.g., Brown, 1989, 1996; Firestein, 1996; Kitzinger, 2001) have called for psychological science to undergo a paradigm shift and for psychologists to adopt the lens of sexual minority perspec-

\footnotetext{
${ }^{1}$ Department of Psychology, University of Michigan, Ann Arbor, Michigan.

${ }^{2}$ Department of Psychology, University of Connecticut, Storrs, Connecticut.

${ }^{3}$ To whom correspondence should be addressed at Department of Psychology, University of Michigan, 525 E. University, Ann Arbor, Michigan 48109-1109; e-mail: jkonik@umich.edu.
}

tives in order to gain new insights on the human experience. An exploration of the psychological wellbeing and resilience of sexual minorities, who create and maintain their sexual identities in a society punctuated with homophobia, can lead to a better understanding of how socially marginalized "others" achieve psychological growth.

One specific area of LGB psychological strength has been proposed by Brown (1989), who suggested that by being "normatively different" LGBs develop greater creativity than heterosexuals in generating scripts for their lives. She provided the example of Clunis and Green's research (Clunis \& Green, 1988) with lesbian couples. Because the women in their study had few models of how to be a lesbian in a committed relationship, they were left to improvise ways to live their lives. As Brown (1989) summarized, “... by lacking clear rules about how to be lesbian and gay in the world, we have made up the rules as we go along" (p. 451).

Brown's theory of normative creativity suggested to us the intriguing notion that LGB individuals might score higher than heterosexuals on a measure of cognitive flexibility. Cognitive flexibility 
is defined as "a person's (a) awareness that in any given situation there are options and alternatives available, (b) willingness to be flexible and adapt to the situation, and (c) self-efficacy or belief that one has the ability to be flexible" (Martin \& Anderson, 1998, p. 1).

To date, only a few empirical studies of gender and sexuality have included cognitive flexibility as a construct of interest. In a study of gender role orientation, Carter (1985) suggested that androgynous individuals may demonstrate more cognitive flexibility because their personalities incorporate both traditionally feminine and masculine traits. Carter's data supported this theory to a limited degree, as androgynous individuals scored higher on a measure of cognitive flexibility than did those who were feminine or undifferentiated (i.e., low on both traditionally feminine and masculine traits). There were no other significant differences in cognitive flexibility by gender role orientation in this study. However, Windle (1986) found no systematic differences in cognitive flexibility by gender role orientation. It appears that future research is necessary to understand fully the relationship between gender role orientation and cognitive flexibility.

Similar to androgyny's incorporation of feminine and masculine traits, bisexuality involves aspects of both same-sex and cross-sex sexuality. Zinik (1985) theorized a "flexibility model of bisexuality" (p. 7) that proposes that bisexuals possess high levels of cognitive flexibility, as they traverse between heterosexual and homosexual communities. To our knowledge, only one (unpublished) study has been conducted on the relationship between cognitive flexibility and sexuality. Zinik (1983) used Troldahl and Powell's Short-Form Dogmatism Scale (Troldahl \& Powell, 1965)to measure cognitive flexibility. This measure is based on Rokeach's Dogmatism Scale (Rokeach, 1960)and conceptualization of dogmatism as the degree of openness or closedness in one's cognitive systems. Zinik's 419 participants included 64 heterosexual men, 103 heterosexual women, 61 gay men, 53 lesbians, 74 bisexual men, and 64 bisexual women. All heterosexual participants were students in undergraduate human sexuality courses at the University of California at Santa Barbara, and lesbian, gay, and bisexual participants were recruited from sexual minority social and support organizations in California.

Zinik's results provided only limited support for a relationship between sexual identity and cognitive flexibility, as bisexual women scored lowest in dog- matism, followed by heterosexual women, lesbians, gay men, heterosexual men, and bisexual men, respectively. Although the effect of participant sex was significant, there was no effect for sexual identity category (heterosexual, lesbian/gay, or bisexual), and the interaction between participant sex and sexual identity was marginal. Zinik proposed that the main effect for sex may be attributable to the inappropriateness of using a dogmatism scale to measure cognitive flexibility, to the dogmatism scale's insensitivity to ideological changes that occurred during the women's movement (which may have led women to score lower on the scale), or to self-selection among the bisexual female participants. Zinik proposed that his research be replicated using more comprehensive measures of cognitive flexibility. The present study was designed to do that.

In light of Brown's theory of sexual minority normative creativity (Brown, 1989), we hypothesized that lesbian, gay, and bisexual participants would score higher than heterosexuals on a measure of cognitive flexibility.

\section{METHOD}

\section{Participants}

Participants in this study were 358 undergraduate and graduate students. They were recruited in their classes at an eastern university, and some received course credit for their participation. To find more LGB participants, surveys were also distributed at LGB and LGB-friendly conferences, student organization meetings, and on e-mail listserves. Because of the snowball-sampling method utilized in this study (we distributed surveys to those involved in the LGB community and requested that they distribute them to others), an exact response rate could not be calculated.

Two hundred and two participants identified themselves as heterosexual, 100 as gay or lesbian, 40 as bisexual, 14 as "other," one chose not to identify sexual orientation, and one had missing data for this question (the page with this item was detached from the survey). Ninety-eight participants were men, 257 were women, and three were transgendered. The mean age was 22.3 years, with a standard deviation of 5.6 years. The sample was predominantly European American; $83.9 \%$ identified themselves as European American, $5.9 \%$ as African American, $2.5 \%$ as Asian American, $3.1 \%$ as Latino/a, and $4.5 \%$ as "other." 


\section{Measures}

The Cognitive Flexibility Scale (Martin \& Rubin, 1995) was used to assess participants' perceptions of the options and alternatives available to them in everyday situations. Questions from this scale include: "I can find workable solutions to seemingly unsolvable problems" and "In any given situation, I am able to act appropriately." The scale consists of 12 items on a 6-point Likert scale, which are summed to obtain a total score, $M=55.46, S D=$ 7.34 (Martin \& Rubin, 1995). This scale demonstrated an internal consistency rating of .76, and a test-retest reliability of .83 (Martin \& Rubin, 1995), and the internal consistency for this measure in this study was .77 .

Several studies have supported the validity of the Cognitive Flexibility Scale, as it positively correlated with self-insight (Grant, Franklin, \& Langford, 2002), tolerance for disagreement (Martin, Anderson, \& Thweatt, 1998), multicultural sensitivity (Kim, Cartwright, Asay, \& D'Andrea, 2003), social flexibility (Singelis, Hubbard, Her, \& An, 2003), communication flexibility (Martin \& Rubin, 1995), assertiveness, and responsiveness (Martin \& Anderson, 1998). The Cognitive Flexibility Scale also negatively correlated with rigidity of attitudes regarding personal habits (Martin \& Rubin, 1995).

Sexual identity was assessed via a self-report item. The question read: "How would you identify your sexual orientation? Please circle the most accurate response. Please circle only one response." The response options included heterosexual, homosexual (gay or lesbian), bisexual, other (with space for an explanation of this response), and choose not to identify.

\section{Procedure}

Participants were given (in person or by mail) a packet of surveys that consisted of a demographic information sheet, six questions about sexual identity and preferences, and The Cognitive Flexibility Scale. ${ }^{4}$ They were asked to complete the packet at their convenience and return it by mail in a postpaid envelope. Participants also received a letter inform-

\footnotetext{
${ }^{4}$ Data presented here are part of a larger study on sexual identity and overall identity development. Results from other surveys administered at this same time are reported elsewhere (Konik \& Stewart, in press).
}

ing them that they were not obligated to participate in this research and that they were expressing their consent to be participants by completing the survey.

\section{RESULTS}

A $3 \times 2$ analysis of variance (ANOVA) was conducted using cognitive flexibility scores as the dependent variable and self-identified sexual orientation (heterosexual, lesbian/gay, or bisexual/other) and participant sex (male or female) as the independent variables. The three transgendered participants, the one who did not label her sexuality, and the one with a missing response to this question were excluded from the analysis. Participants who labeled their sexual identity as "other" were combined with bisexuals because the labels they provided for their sexuality (e.g., "biaffectionate," "queer") reflected a "nonexclusive" identity that is not restricted to attraction toward only one sex. Thus, the sexual identity groups consisted of heterosexual $(n=202)$, lesbian/gay $(n=100)$, and bisexual/other participants $(n=54)$.

The ANOVA indicated a significant effect for sexual identity, $F(2,349)=4.07, p=.02$. There was no effect for participant sex, $F(1,349)=0.19, p=$ .66 , and the interaction between sex and sexual identity was not significant, $F(2,349)=1.87, p=.16$, $R^{2}=.036$. Tukey post hoc tests revealed that participants with a nonexclusive sexual identity scored higher on cognitive flexibility than did those who identified as heterosexual or lesbian/gay, $p<.05$. No significant differences were found between heterosexuals and lesbians/gays on cognitive flexibility, $p=$ .99 (see Table I).

A follow-up analysis was conducted to test the possibility that this effect was due to the "other" group, as they may have rejected all of the standard categories of sexual identity. To test this possibility, we conducted an ANOVA to compare participants with exclusive sexual identities (heterosexual, lesbian, or gay) and those with nonexclusive sexual

Table I. Means and Standard Deviations for Cognitive Flexibility Scale Scores as a Function of Sexual Identity

\begin{tabular}{lcc}
\hline & $M$ & $S D$ \\
\hline Heterosexual ( $n=42$ men, 160 women) & $58.73^{a}$ & 5.10 \\
Lesbian/gay $(n=45$ men, 55 women) & $58.65^{a}$ & 6.32 \\
Bisexual/other $(n=8$ men, 31 women) & $60.94^{b}$ & 5.11 \\
Total & 59.01 & 5.52 \\
\hline
\end{tabular}

Note. Means with different superscripts differed at $p<.05$. 
identities (bisexual); the "other" identified participants were excluded from this analysis. As in the results presented above, participants with a nonexclusive bisexual identity $(M=60.87, S D=5.20)$ scored higher on cognitive flexibility than did those with an exclusive heterosexual, lesbian, or gay identity $(M=58.70, S D=5.52), F(1,338)=5.25, p=.02$, $R^{2}=.025$.

\section{DISCUSSION}

The results of this study contrast with those reported by Zinik (1983) and provide preliminary insights into a possible relationship between sexual identity and cognitive flexibility. Both men and women with a nonexclusive sexual identity scored higher on a measure of cognitive flexibility than did heterosexuals or lesbians/gay men; there was no significant difference between the latter two groups.

Unlike Zinik (1983), who found that men scored higher on dogmatism, we obtained no effects for sex of participant. This difference could be due to the type of measure used (dogmatism vs. cognitive flexibility). Alternatively, shifts in gender roles in the two decades since Zinik's study may have decreased sex differences in dogmatism.

It is interesting that our gay and lesbian participants did not differ from our heterosexual participants in cognitive flexibility scores. As university students in their early 20s, these participants are constructing their sexual identities in a time of increasing social acceptance for sexual minorities. Although homophobia is still rampant in our society, attitudes toward sexual minorities are gradually becoming more favorable (Herek, 2002). However, one recent study of heterosexual undergraduates showed that bisexuals in general (and bisexual men in particular) were viewed more negatively than were either lesbians or gay men (Eliason, 1997). It seems that, although attitudes toward gay men and lesbians have become more favorable, bisexuals and those with a nonexclusive sexual identity still are viewed as most deviant.

One interesting direction for future research is to explore the issue of cognitive flexibility and sexual identity among transgendered individuals. The process of sexual identity formation and maintenance in transgendered populations is one that warrants future attention, as the categories of sexual identity are exceptionally complex in transgendered communities (e.g., If a preoperative female-to-male transgendered woman is engaged in a sexual relation- ship with a biological female who identifies as a man, would this person's sexual identity be homosexual, heterosexual, bisexual, or something else?) The norms for sexual identity development among transgendered individuals appear to be quite fluid, and, consequently, the role of cognitive flexibility in developing these norms is an interesting topic for future research. ${ }^{5}$

One limitation of Zinik's study and our own is that both used single self-report measures of cognitive flexibility. Further investigations with multiple measures of cognitive flexibility [e.g., the Alternate Uses Test (Wilson, Christensen, Merrifield, \& Guilford, 1960), the Test of Behavioral Rigidity (Schaie, 1955), and anagram word puzzles (Walker, Liston, Hobson, \& Stickgold, 2002)] would lead to a more nuanced view of what kinds of creativity and flexibility are linked with sexual identity. Also, considering the limited number of participants with nonexclusive sexual identities in this study, further research with a greater number of such participants would help to determine whether these results are replicable.

Perhaps our most intriguing finding is that differences in cognitive flexibility were not found between heterosexuals and gay/lesbian participants despite the greater power provided by the sample size of these two populations. Instead, the difference that emerged was between those with exclusive and nonexclusive sexual identities. Our study has demonstrated that individuals who are most flexible about the gender of their sexual and affectional partners also show flexibility outside the realm of sexuality, in their overall cognitive style. This is a novel finding that may reflect normative openness and creativity in those with nonexclusive sexual identities.

\section{ACKNOWLEDGMENT}

This project was partially supported by a Jacob K. Javits Fellowship.

\section{REFERENCES}

Bayer, R. (1987). Homosexuality and American psychiatry. Princeton, NJ: Princeton University Press.

Bohan, J. (1996). Psychology and sexual orientation: Coming to terms. New York: Routledge.

Brown, L. S. (1989). New voices, new visions: Toward a lesbian/gay paradigm for psychology. Psychology of Women Quarterly, $13,445-458$.

\footnotetext{
${ }^{5} \mathrm{We}$ are indebted to an anonymous reviewer for this suggestion.
} 
Carter, D. B. (1985). Relationships between cognitive flexibility and sex-role orientation in young adults. Psychological Reports, 57, 763-766.

Clunis, D. M., \& Green, G. D. (1988). Lesbian couples. Seattle: Seal Press.

Eliason, M. J. (1997). The prevalence and nature of biphobia in heterosexual undergraduate students. Archives of Sexual Behavior, 26, 317-326.

Firestein, B. A. (Ed.). (1996). Bisexuality: The psychology and politics of an invisible minority. Thousand Oaks, CA: Sage.

Grant, A. M., Franklin, J., \& Langford, P. (2002). The SelfReflection and Insight Scale: A new measure of private selfconsciousness. Social Behavior and Personality, 30, 821-836.

Herek, G. M. (2002). Gender gaps in public opinion about lesbians and gay men. Public Opinion Quarterly, 66, 40-66.

Kim, B. S. K., Cartwright, B. Y., Asay, P. A., \& D’Andrea, M. J. (2003). A revision of the Multicultural Awareness, Knowledge, and Skills Survey-Counselor edition. Measurement and Evaluation in Counseling and Development, 36, 161-180.

Kitzinger, C. (2001). Sexualities. In R. K. Unger (Ed.), Handbook of the psychology of women and gender (pp. 272-285). New York: Wiley.

Konik, J., \& Stewart, A. (2004). Sexual identity development in the context of compulsory heterosexuality. Journal of Personality, $22,815-844$.

Martin, M. M., \& Anderson, C. M. (1998). The Cognitive Flexibility Scale: Three validity studies. Communication Reports, 11, $1-9$.

Martin, M. M., Anderson, C. M., \& Thweatt, K. S. (1998). Aggressive communication traits and their relationships with the
Cognitive Flexibility Scale and the Communication Flexibility Scale. Journal of Social Behavior and Personality, 13, 531-540.

Martin, M. M., \& Rubin, R. B. (1995). A new measure of cognitive flexibility. Psychological Reports, 76, 623-626.

Rokeach, M. (1960). The open and closed mind. New York: Basic Books.

Schaie, K. W. (1955). A test of behavioral rigidity. Journal of $A b$ normal and Social Psychology, 51, 604-610.

Singelis, T. M., Hubbard, C., Her, P., \& An, S. (2003). Convergent validation of the Social Axioms Survey. Personality and Individual Differences, 34, 269-282.

Troldahl, V. C., \& Powell, F. A. (1965). A short-form dogmatism scale for use in field studies. Social Forces, 44, 211-214.

Walker, M. P., Liston, C., Hobson, A., \& Stickgold, R. (2002). Cognitive flexibility across the sleep-wake cycle: REM-sleep enhancement of anagram problem solving. Cognitive Brain Research, 14, 317-324.

Wilson, R. C., Christensen, P. R., Merrifield, P. R., \& Guilford J. P. (1960). Alternate Uses, Form A: A manual of administration, scoring, and interpretation. Beverly Hills, CA: Sheridan Supply.

Windle, M. (1986). Sex role orientation, cognitive flexibility, and life satisfaction among older adults. Psychology of Women Quarterly, 10, 263-273.

Zinik, G. A. (1983). The relationship between sexual orientation and eroticism, cognitive flexibility, and negative affect. Unpublished doctoral dissertation, University of California, Santa Barbara

Zinik, G. A. (1985). Identity conflict or adaptive flexibility? Bisexuality reconsidered. Journal of Homosexuality, 11(1/2), 7-19. 